\title{
Note
}

\section{Effects of Cooking Conditions on the Relationships Among Oxalate, Nitrate, and Lutein in Spinach}

\author{
Zheng Wang, Akira Ando, Atsuko TAKeuchi and Hiroshi UedA* \\ Division of Vegetable Pest Management and Functional Analysis, Institute of Vegetable and Floriculture Science, \\ National Agriculture and Food Research Organization, 360 Kusawa, Anou, Tsu, Mie 514-2392, Japan
}

Received November 20, 2017 ; Accepted January 18, 2018

This study sought to determine the optimal cooking conditions under which lutein would be maintained while oxalic acid and nitrate ion would be removed. The effects of cooking temperature and time control on the concentration of oxalic acid, nitrate ion, and lutein in spinach were investigated. The results demonstrated that boiling at $100^{\circ} \mathrm{C}$ for $2 \mathrm{~min}$ was the optimal cooking condition. This preserved approximately $77 \%$ of lutein while $67 \%$ of oxalic acid and $30 \%$ of nitrate ion were removed. If nitrate ion is disregarded, we also found that submerging in hot water at $60^{\circ} \mathrm{C}$ for $30 \mathrm{~s}$ was another optimal condition. In this case, $96 \%$ of lutein remained, $28 \%$ of oxalic acid was removed, whereas the content of nitrate ion was unchanged.

Keywords: spinach, lutein, oxalate, nitrate ion, cooking processing

\section{Introduction}

Spinach (Spinacia oleracea L.) is an important green leafy vegetable due to its diverse nutritional composition, including vitamins, minerals, and phytochemicals. Spinach is one of the richest plant sources of lutein, which selectively accumulates in the retinal macular area of the eye (Sommerburg et al., 1998; Perry et al., 2009; Abdel-Aal et al., 2013). It is involved in the prevention of age-related macular degeneration and cataracts (Wong et al., 2011). However, oxalate and nitrate are also naturally occurring contents in plants and are found to have relatively high levels in spinach. Oxalate can combine easily with calcium and magnesium to form insoluble oxalate crystals and inhibit calcium or magnesium absorption in humans (Mou, 2008; Genannt Bonsmann et al., 2008; Arias-Carmonal et al., 2014). High levels of oxalates in the diet can lead to the irritation of the digestive system and the formation of kidney stones (Holmes et al., 2000). Similarly, the amount of nitrate ion in vegetables is an important indicator in food safety evaluation. The intake of vegetables containing a high concentration of nitrate ion can cause infantile methemoglobinemia, cancer, and other diseases (Pennington, 1998; Sanchez-Echaniz et al., 2001). However, there is controversy as to whether nitrate ion in our diets is beneficial or harmful, and it has been reported that nitrate ion is beneficial for health (Bahadoran et al., 2015).

Vegetables are usually consumed in raw and cooked forms. Total and soluble oxalate contents of some raw and/or boiled vegetables have been reported by several groups. For instance, Hönow et al. (2002) compared the oxalate content of fruits, vegetables, and other foods such as nuts and cereal crops. Savage et al. (2000) reported that soluble oxalate can be removed by boiling. Chai et al. (2005) showed that the boiling process markedly reduced the soluble oxalate content more effectively than steaming and baking processes. Abo Bakr et al. (1986) reported the lower nitrate content after cooking vegetables. Moreover, Izumi et al. (2005) evaluated the influence of different amounts of boiling water on oxalic acid in spinach. The result showed that greater the amount of boiling water, greater was the decrease in the concentration of oxalic acid. Recently, Kojima et al. (2017) reviewed the loss of vitamins under various cooking conditions. In spinach, 36\%$73 \%$ of vitamin $\mathrm{C}$ was lost under different boiling conditions.

However, a few studies have focused on the relationships among oxalate, nitrate, and lutein contents during the cooking process. Thus, the purpose of this study was to investigate the 
effects of different cooking conditions on the changes of oxalate, nitrate, and lutein contents in spinach. The goal was to optimize the cooking conditions that can retain lutein and simultaneously remove oxalate and nitrate contents in spinach.

\section{Materials and Methods}

Materials Fresh spinach (Spinacia oleracea L., 'Jasuteisu' cultivar), which was cultivated in the Ibaraki Prefecture, was purchased from a local supermarket on June 27, 2017. Standard lutein, oxalic acid, potassium nitrate, sodium hydroxide, and 2,6-pyridinedicarboxylic acid were purchased from Wako Pure Chemical Industries (Osaka, Japan). Pyrogallol and all organic solvents were of analytical or HPLC grade and purchased from Kanto Chemical Co., Inc. (Tokyo, Japan). Hexadecyltrimethylammonium bromide (purity $\geqq 99.0 \%$ ) was purchased from Nacalai Tesque, Inc. (Kyoto, Japan).

Sample preparation The fresh spinach $(\mathrm{n}=6)$ was boiled with $3 \mathrm{~L}$ of tap water at different temperatures $\left(60^{\circ} \mathrm{C}, 80^{\circ} \mathrm{C}\right.$, and $100^{\circ} \mathrm{C}$ ) and for a duration of $30 \mathrm{~s}, 1 \mathrm{~min}, 2 \mathrm{~min}$, and $3 \mathrm{~min}$, respectively. Water bath was used for conditions at $60^{\circ} \mathrm{C}$ or $80^{\circ} \mathrm{C}$ and $\mathrm{IH}$ cooking heater for $100^{\circ} \mathrm{C}$. The temperatures decreased after putting in spinach. The cooking time was counted when the temperatures returned to starting conditions. The boiled spinach was rinsed under running water $(<1 \mathrm{~min})$. Squeezing spinach, the excess water was removed using Kimtowels (Nippon Paper Crecia, Tokyo, Japan). All samples were stored at $-20^{\circ} \mathrm{C}$ until analysis.

Saponification and extraction procedure Saponification and extraction methods were developed, which were modified from the methods described by Yasui et al. (2015). Frozen spinach was cut into small pieces and immediately crushed using a family use mixer (MJ-M30, National, Tokyo, Japan) after mixing with $3 \times$ volume of pyrogallol/ethanol solution $(3 \%, w / v)$. One milliliter of crushed spinach solution was transferred into a 50-mL centrifuge tube. Ten milliliters of pyrogallol/ethanol solution $(3 \%, \mathrm{w} / \mathrm{v})$ and $1 \mathrm{~mL}$ of potassium hydroxide $(60 \%, \mathrm{w} / \mathrm{v})$ were added, and the contents were mixed using a vortex mixer. Furthermore, the tube was incubated for $15 \mathrm{~min}$ at $60^{\circ} \mathrm{C}$ in a shaking water bath (Personal-11, TAITEC, Saitama, Japan) at 160 strokes/min. After saponification, the tubes were cooled under running water. A solution containing $22.5 \mathrm{~mL}$ of sodium chloride $(1 \%$, $\mathrm{w} / \mathrm{v})$ and $15 \mathrm{~mL}$ of ethyl acetate/n-hexane $(1: 9, \mathrm{v} / \mathrm{v})$ was added into the tube and kept at room temperature with vibration for $5 \mathrm{~min}$. Then the mixture was centrifuged at $6000 \times \mathrm{g}$ for $5 \mathrm{~min}$ and the organic layer containing lutein was collected. This extraction procedure was repeated for 2 times. The collected organic layers were evaporated to dryness by a centrifugal evaporator (CVE-3100, EYELA, Tokyo, Japan). The dry residue containing lutein was dissolved in $10 \mathrm{~mL}$ of ethanol for determination by HPLC.

Determination of lutein content The HPLC system consisted of a PU-2080 Plus pump (JASCO, Tokyo, Japan), a
MD-2015 plus diode array detector (JASCO, Tokyo, Japan), and a Develosil XG C-30 M column $(4.6 \times 250 \mathrm{~mm}$ i.d., Nomura Chemical Co., Ltd., Aichi, Japan) with a particle size of $5 \mu \mathrm{m}$. The column was protected by a guard column (XGC30, Nomura Chemical Co., Ltd., Aichi, Japan) of the same packing material. The mobile phase was acetonitrile/methanol $(65: 35, \mathrm{v} / \mathrm{v})$, and the flow rate was $1 \mathrm{~mL} / \mathrm{min}$. The column oven temperature was $40^{\circ} \mathrm{C}$. The volume injected was $20 \mu \mathrm{L}$, and the lutein peak was detected at $450 \mathrm{~nm}$. All samples were filtered by a $0.45-\mu \mathrm{m}$ pore size hydrophobic PTFE membrane before determination by HPLC.

Extraction and determination of oxalate and nitrate content Frozen spinach was cut into small pieces and mixed with $4 \times$ the volume of Milli-Q water in a beaker. The inactivation of enzymes was performed in a microwave oven (NE-M150, National, Tokyo, Japan) until the Milli-Q water was heated to nearly boiling $(<5 \mathrm{~min})$. Following this, it was cooled under running water and crushed by a family use mixer (MJ-M30, National, Tokyo, Japan). The mixture was then centrifuged at $15000 \mathrm{rpm}$ for $5 \mathrm{~min}$, and the supernatant was collected and diluted 4 times with Milli-Q water. All the samples were filtered using a $0.45-\mu \mathrm{m}$ pore size hydrophobic PTFE membrane before determination by a capillary electrophoresis (CE) system (Model 7100, Agilent Technologies, Palo Alto, CA, USA) equipped with a diode array detector. An uncoated fused-silica capillary of $100 \mathrm{~cm}(91.5 \mathrm{~cm}$ effective length, $50 \mu \mathrm{m}$ i.d.) purchased from GL Sciences Inc. (Tokyo, Japan). The CE method used in this study for the determination of oxalate and nitrate contents was a modified form of the methods described by Soga et al. (1999) and Horie (2009). The running buffer contained $20 \mathrm{mM}$ 2,6-pyridinedicarboxylic acid, and $0.5 \mathrm{mM}$ hexadecyltrimethylammonium bromide. The $\mathrm{pH}$ of running buffer was adjusted to 12.1 using $1 \mathrm{~N}$ sodium hydroxide. The standards and samples were injected into the capillary with a pressure of 50 mbar for $5 \mathrm{~s}$. The separation voltage applied was $-30 \mathrm{kV}$, and detection was performed with a diode array detector at wavelengths of $350 \mathrm{~nm}$ with a reference at $270 \mathrm{~nm}$. The temperature of the capillary was controlled at $25^{\circ} \mathrm{C}$. For successive electrophoretic runs, the capillary was rinsed sequentially with methanol, $0.1 \mathrm{~N}$ sodium hydroxide, and the running buffer for $5 \mathrm{~min}$, respectively. The mixture of working standard was prepared by dissolving oxalic acid and potassium nitrate in Milli-Q water with concentrations of 400 and $200 \mathrm{mg} / \mathrm{L}$ (nitrate ion), respectively. Oxalate and nitrate were measured as oxalic acid and nitrate ion, respectively.

Statistical analysis Statistical analysis was performed using the EXCEL Statistics version 7.0 (Esumi Co., Ltd., Tokyo, Japan). Data were reported as mean $\pm \mathrm{SE}(\mathrm{n}=6)$. Twoway repeated measures analysis of variance was performed to analyze the effects of the various cooking temperatures and cooking times on oxalate, nitrate, and lutein contents at a confidence level of $95 \%(p<0.05)$. A least significant 
difference test with a $95 \%$ confidence level was used to compare differences between the treatments.

\section{Results and Discussion}

This study was performed to assess the relationships among oxalate, nitrate, and lutein contents in spinach under different cooking conditions. Previous studies have found that oxalate can bind with calcium ions to form calcium oxalate crystals in the mouth (Tanaka et al., 2003; Perera et al., 1990). Additionally, Horie et al. (2006) reported that water-insoluble oxalic acid can unlikely affect the taste of spinach. Therefore, this study primarily focused on water-soluble oxalic acid. The concentrations of oxalic acid in raw spinach were $362 \pm 18 \mathrm{mg}$ of $100 \mathrm{~g}$ of fresh weight $(\mathrm{FW}$ ) (mean $\pm \mathrm{SE}, \mathrm{n}=6$ ). The variety and environmental factors could affect the biosynthesis and level of oxalate in spinach. For instance, Mou (2008) investigated that there were significant differences in oxalate concentration among the genotypes using 11 commercial cultivars of spinach. After cooking for $30 \mathrm{~s}$, oxalic acid concentrations were significantly reduced at all treated temperatures $(p<0.05)$. More than $30 \%$ of oxalic acid was removed at different cooking temperatures $\left(60^{\circ} \mathrm{C}, 80^{\circ} \mathrm{C}\right.$, and $100^{\circ} \mathrm{C}$ ) for $30 \mathrm{~s}$, and $40 \%$ of oxalic acid was removed at $100^{\circ} \mathrm{C}$ after 1 min with 16.7 times the amount of water. This result agrees with that of Izumi et al. (2005), wherein they report that $50 \%$ of oxalic acid can be removed after boiling at $100^{\circ} \mathrm{C}$ for 1 min with 20 times the amount of spinach weight of boiling water. Oxalic acid concentration was significantly decreased after 2 and $3 \mathrm{~min}(67 \%$ and $73 \%$, respectively, $p<0.05)$ at $100^{\circ} \mathrm{C}$, whereas there was nearly no change after treating at $60^{\circ} \mathrm{C}$ and $80^{\circ} \mathrm{C}$ (Figure 1). The results indicate that oxalic acid can easily be removed by hot water treatment (e.g. $60^{\circ} \mathrm{C}$ for $30 \mathrm{~s}$ ). Compared with $60^{\circ} \mathrm{C}$ and $80^{\circ} \mathrm{C}$, more than twice the amount of oxalic acid was removed at $100^{\circ} \mathrm{C}$ for $2 \mathrm{~min}$. It was considered that higher temperature and longer cooking time can break down the tissues of spinach and improve the release of oxalic acid. Other factors, such as the tissue condition of spinach, can also promote the release of oxalic acid. Izumi (2004) reported that the cell wall contained a smaller amount of cellulose and was thinner in summer due to short growing periods, which may result in quick tissue damage and the release of oxalic acid. Izumi et al. (2005) also showed that the leaf blade containing oxalic acid was softer than the petiole containing nitrate; therefore, oxalic acid can easily be removed during boiling.

The concentrations of nitrate ion in raw spinach were $386 \pm$ $25 \mathrm{mg}$ of $100 \mathrm{~g} \mathrm{FW}$ (mean $\pm \mathrm{SE}, \mathrm{n}=6$ ). The environmental conditions, nitrogen fertilization regime, temperature, and use of herbicides can also increase the plant nitrate content (Iammarino et al., 2014). Figure 2 shows the changes of nitrate ion concentration in spinach after different cooking conditions. The remains of nitrate ion depended on the cooking temperature and time. Compared with $60^{\circ} \mathrm{C}$ and $80^{\circ} \mathrm{C}$, the

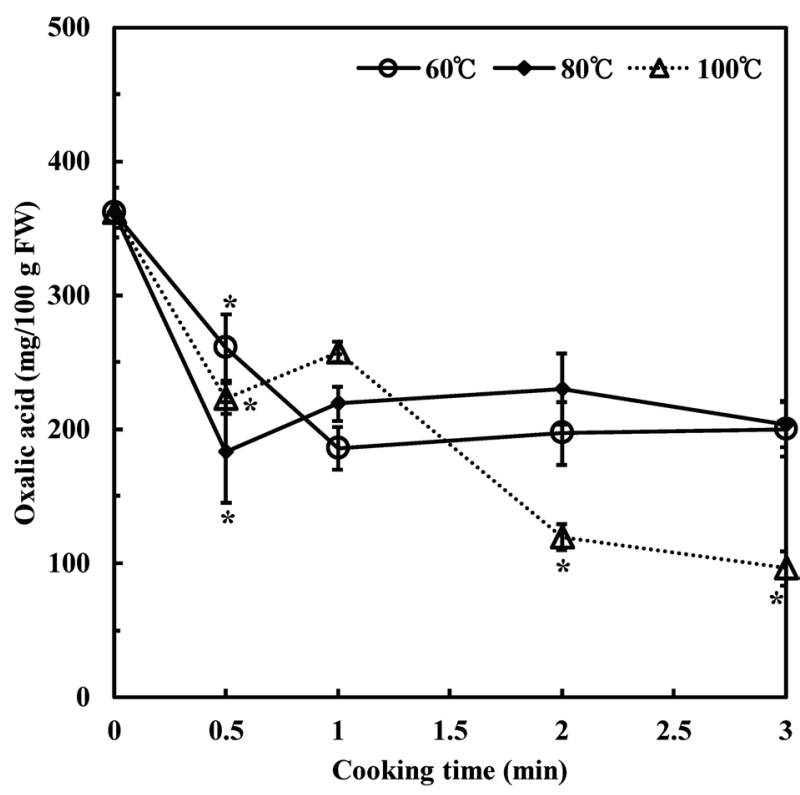

Fig. 1. Effects of cooking times and cooking temperatures on the changes of oxalic acid concentration. Error bars indicate SE ( $\mathrm{n}=$ 6). Asterisks indicate significant differences (two-way repeated measures analysis of variance, $\mathrm{p}<0.05$ ).

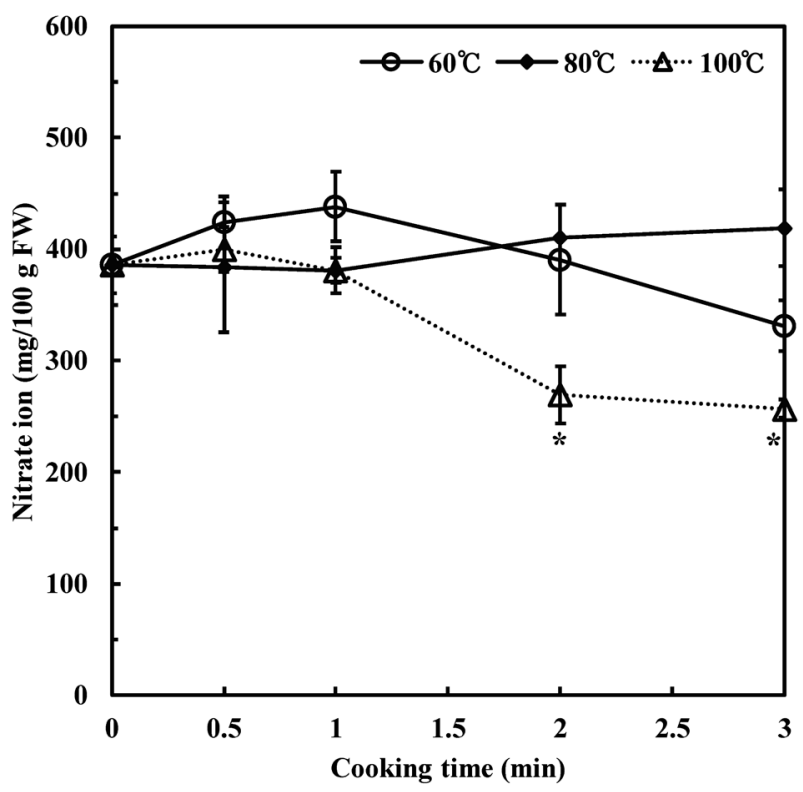

Fig. 2. Effects of cooking times and cooking temperatures on the changes of nitrate ion concentration. Error bars indicate SE ( $\mathrm{n}=$ 6). Asterisks indicate significant differences (two-way repeated measures analysis of variance, $p<0.05)$.

concentrations of nitrate ion in boiled spinach at $100^{\circ} \mathrm{C}$ were reduced to $70 \%$ and $67 \%$ at 2 and $3 \mathrm{~min}$, respectively ( $p<$ $0.05)$. These results indicated that oxalic acid contents can be removed more easily than nitrate ion contents at the same cooking conditions. For nitrate ion removal, it was required to boil the spinach at $100^{\circ} \mathrm{C}$ only for $2-3 \mathrm{~min}$.

The cultivar and environmental conditions can affect the lutein content in spinach (Oowashi et al., 2014). The 


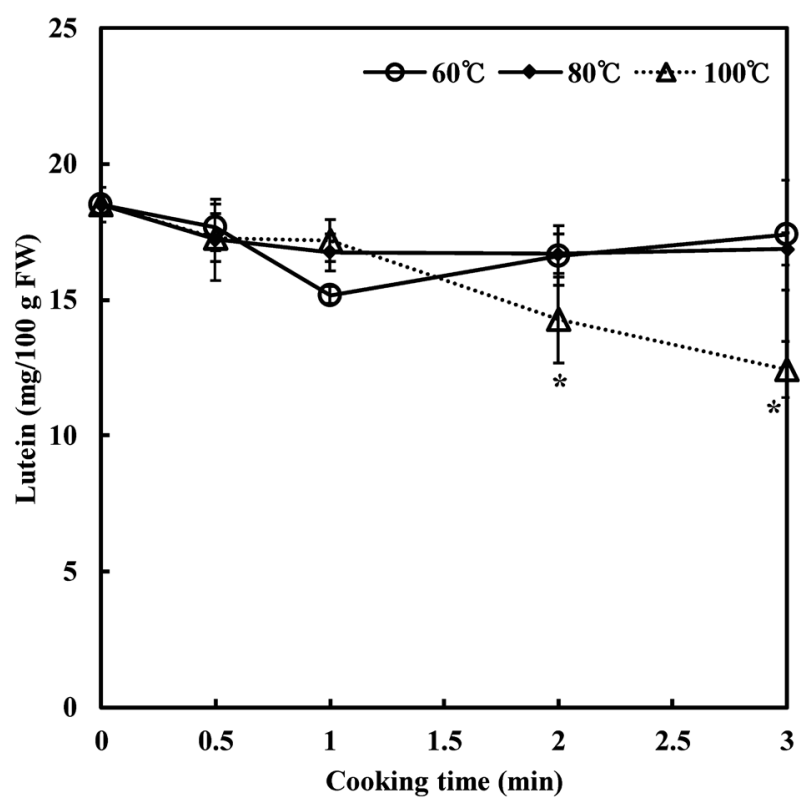

Fig. 3. Effects of cooking times and cooking temperatures on the changes of lutein concentration. Error bars indicate SE $(n=$ 6). Asterisks indicate significant differences (two-way repeated measures analysis of variance, $p<0.05$ ).

concentrations of lutein in raw spinach were $18.5 \pm 0.6 \mathrm{mg}$ of $100 \mathrm{~g} \mathrm{FW}$ (mean $\pm \mathrm{SE}, \mathrm{n}=6$ ). The remaining lutein concentration in spinach after cooking is shown in Figure 3. The lutein concentration was significantly decreased at $100^{\circ} \mathrm{C}$ for $2 \mathrm{~min}$ and approximately $77 \%$ of lutein remained ( $p<$ $0.05)$. In contrast, it was slightly decreased when the spinach was cooked at $60^{\circ} \mathrm{C}$ or $80^{\circ} \mathrm{C}$ for $2 \min (<10 \%)$. This result suggested that the cooking temperature and cooking time can affect the stability of lutein in spinach. Approximately 50\% decrease of lutein was reported in spinach with different storage methods or boiling time (Bunea et al., 2008).

Oxalate, nitrate, and lutein can be synthesized by plants with different precursors and pathways in leaves, stems, and storage tissues (Betsche et al., 2005). Each component can be released with different cooking conditions. The release behavior of each component depends on the chemical properties and/or the chemical forms of each component in plants. In future, sensory evaluation is also required for spinach processed with each condition. In this study, our results showed that oxalic acid and nitrate ion of vegetables can be removed by the process of cooking in boiling water. However, many beneficial compounds such as lutein and vitamins may be damaged. The results of this study optimized the best condition $\left(100^{\circ} \mathrm{C}\right.$ for $\left.2 \mathrm{~min}\right)$ to remove oxalate and nitrate ion in spinach while keeping as much the lutein content as possible. Moreover, previous studies have shown that dietary consumption of nitrate ion has numerous health benefits such as anti-inflammation, regulation of glucose homeostasis and insulin signaling pathway, and also improvement of cardiovascular function (Bahadoran, et al., 2015; Bedale et al.,
2016; Bondonno et al., 2016; Delmastro-Greenwood et al., 2015). From this perspective, another optimized condition can be suggested as following. $28 \%$ of oxalic acid can be removed while $96 \%$ of lutein can be remained at $60^{\circ} \mathrm{C}$ for $30 \mathrm{~s}$. However, although the beneficial properties related to nitrate ion have been investigated in different experiments, it is necessary to confirm the effects by long-term clinical studies with various doses of inorganic nitrate supplementation.

Acknowledgements This research was supported by grants from the Project of the NARO Bio-oriented Technology Research Advancement Institution (the special scheme project on regional developing strategy). We also thank Ms. Takako Hayashi and Ms. Kyoko Nozawa for her help with our experiments.

\section{References}

Abo Bakr, T.M., El-Iraqui, S.M., and Huissen, M.H. (1986). Nitrate and nitrite contents of some fresh and processed Egyptian vegetables. Food Chem., 19, 265-275.

Abdel-Aal, el-S.M., Akhtar, H., Zaheer, K., and Ali, R. (2013). Dietary sources of lutein and zeaxanthin carotenoids and their role in eye health. Nutrients, 5, 1169-1185.

Arias-Carmona1, M.D., Romero-Rodríguez1, M.Á., and VázquezOdériz, M.L. (2014). Determination of organic acids in brassica rapa L. leaves (turnip greens and turnip tops) regulated by the protected geographical indication "Grelos De Galicia”. J. Food Nutr. Res., 2, 786-791.

Bahadoran, Z., Ghasemi, A., Mirmiran, P., Azizi, F., and Hadaegh, F. (2015). Beneficial effects of inorganic nitrate/nitrite in type 2 diabetes and its complications. Nutr. Metab. (Lond), 12, DOI 10.1186/s12986-015-0013-6.

Bedale, W., Sindelar, J. J., and Milkowski, A. L. (2016). Dietary nitrate and nitrite: benefits, risks, and evolving perceptions. Meat Sci., 120, 85-92.

Betsche, T. and Fretzdorff, B. (2005). Biodegradation of oxalic acid from spinach using cereal radicles. J. Agric. Food Chem., 53, 9751-9758.

Bondonno, C. P., Croft, K. D., and Hodgson, J. M. (2016). Dietary nitrate, nitric oxide, and cardiovascular health. Crit. Rev. Food Sci. Nutr., 56, 2036-2052.

Bunea, A., Andjelkovic, M., Socaciu, C., Bobis, O., Neacsu, M., Verhé, R., and Camp, J.V. (2008). Total and individual carotenoids and phenolic acids content in fresh, refrigerated and processed spinach (Spinacia oleracea L.). Food Chem., 108, 649-656.

Chai, W. and Liebman, M. (2005). Effect of different cooking methods on vegetable oxalate content. J. Agric. Food Chem., 53, 3027-3030.

Delmastro-Greenwood, M., Hughan, K. S., Vitturi, D. A., Salvatore, S. R., Grimes, G., Potti, G., Shiva, S., Schopfer, F. J., Gladwin, M. T., Freeman, B. A., and Gelhaus Wendell S. (2015). Nitrite and nitratedependent generation of anti-inflammatory fatty acid nitroalkenes. Free Radic Biol Med., 89, 333-341.

Genannt Bonsmann, S.S., Walczyk, T., Renggli, S., and Hurrell R.F. 
(2008). Oxalic acid does not influence nonhaem iron absorption in humans: a comparison of kale and spinach meals. Eur. J. Clin. Nutr., 62, 336-341.

Horie, H. and Ito H. (2006). Is Oxalate Responsible for the Unpleasant Taste of Spinach Leaves? J. Cookery Sci. Jpn., 39, 357-361 (in Japanese).

Horie, H. (2009). Analysis for the taste compounds in various vegetables by capillary electrophoresis. Bunseki Kagaku, 58, 1063-1066 (in Japanese).

Holmes, R.P. and Kennedy, M. (2000). Estimation of the oxalate content of foods and daily oxalate intake. Kidney Int., 57, 16621667.

Hönow, R. and Hesse, A. (2002). Comparison of extraction methods for the determination of soluble and total oxalate in foods by HPLCenzyme-reactor. Food Chem., 78, 511-521.

Iammarino, M., Di Taranto, A., and Cristino, M. (2014). Monitoring of nitrites and nitrates levels in leafy vegetables (spinach and lettuce): a contribution to risk assessment. J. Sci. Food Agric., 94, 773-778.

Izumi, M. (2004). Seasonal changes in the oxalic acid and potassium contents of spinach and effect of cooking on those contents. $J$. Cookery Sci. Jpn., 37, 268-272 (in Japanese).

Izumi, M., Takaya, M., and Nagasawa, T. (2005). Influence of the amount of boiling water on the sensory evaluation, oxalic acid and potassium content of boiled spinach. J. Cookery Sci. Jpn., 38, 343-349 (in Japanese).

Kojima, A., Ozeki, A., Nkanishi, T., Sato, Y., Chiba, T., Abe, K., and Umegaki, K. (2017). Literature review on vitamin loss from foods during cooking (part 2): Niacin, pantothenic acid, biotin, folic acid, and vitamin C. Vitamins, 91, 87-112 (in Japanese).

Mou B.Q. (2008). Evaluation of oxalate concentration in the U.S. spinach germplasm collection. HortSci., 43, 1690-1693.

Oowashi, T., Kato, H., Takano, I., and Watanabe, M. (2014). Effect of cultivar and environmental condition in lutein content of spinach. Tohoku Agric. Res., 67, 121-122.

Perera, C. O., Hallett. I. C., Nguyen, T. T., and Charles, J. C. (1990). Calcium oxalate crystals: the irritant factor in kiwifruit. J. Food Sci., 55, 1066-1070.

Pennington, J.A.T. (1998). Dietary exposure models for nitrates and nitrites. Food Control, 9, 385-395.

Perry, A., Rasmussen, H., and Johnson, E.J. (2009). Xanthophyll (lutein, zeaxanthin) content in fruits, vegetables and corn and egg products. J. Food Comp. Ana., 22, 9-15.

Sanchez-Echaniz, J., Benito-Fernández, J., and Mintegui-Raso, S. (2001). Methemoglobinemia and consumption of vegetables in infants. Pediatrics., 107, 1024-1028.

Savage, G.P., Vanhanen, L., Mason, S.M., and Ross, A.B. (2000). Effect of cooking on the soluble and insoluble oxalate content of some New Zealand foods. J. Food Compos. Anal., 13, 201-206.

Soga, T. and Ross, G.A. (1999). Simultaneous determination of inorganic anions, organic acids, amino acids and carbohydrates by capillary electrophoresis. J. Chromatogr. A., 837, 231-239.

Sommerburg, O., Keunen, J., Bird, A., and J G M van Kuijk, F. (1998). Fruits and vegetables that are sources for lutein and zeaxanthin: the macular pigment in human eyes. Br. J. Ophthalmol., 82, 907-910.

Tanaka, M., Nakashima, T., and Mori, K. (2003). Formation and distribution of calcium oxalate crystal idioblast in the tissues of taro [Colocasia esculenta (L.) Schott]. J. Jpn. Soc. Hort. Sci., 72, 162-168 (in Japanese).

Wong, Y.I.H., Koo, S.C.Y., and Chan, C.W.N. (2011). Prevention of age-related macular degeneration. Int. Ophthalmol., 31, 73-82.

Yasui, A., Watanabe, T., Nakasato, T., and Fuchigami, K. (2015). Standard tables of food composition in Japan. In "Retinol". Kenpakusha, pp. 113-116. 